\title{
Quality of Life in the COVID-19 Pandemic in India: Exploring the Role of Individual and Group Variables
}

\author{
Korsi Dorene Kharshiing ${ }^{1}$ (D) Drishti Kashyap ${ }^{1} \cdot$ Kaveri Gupta $^{1} \cdot$ Masrat Khursheed $^{1}$. \\ Mohammad Ghazi Shahnawaz ${ }^{1}$. Neda Haseeb Khan ${ }^{1} \cdot$ Ritika Uniyal $^{1}$ • Usama Rehman ${ }^{2}$
}

Received: 20 June 2020 / Accepted: 12 September 2020 / Published online: 21 September 2020

(c) Springer Science+Business Media, LLC, part of Springer Nature 2020

\begin{abstract}
The role of individual variables (COVID-19 anxiety, perceived susceptibility, perceived severity, optimistic bias and personal identity) as predictors of quality of life (QoL) during the novel coronavirus or COVID-19 pandemic is explored. Impact of group related variables (identification to family, religious group and nation) on QoL is also examined. Sample comprised 305 male and female Indian respondents, aged 18 to 78 years. Standardized measures have been utilised to assess the constructs. Results revealed that QoL was significantly influenced by individual variables (COVID-19 anxiety and personal identity) and group variables (identification with family and nation). The effect of COVID-19 anxiety and personal identity as individual variables is over and above that of demographic variables on QoL. Group variables (family and national identification) significantly impacted QoL over and above the individual variables. Findings would indeed, aid in the rehabilitation and assistance of people to live in COVID-19 crisis, and thereafter.
\end{abstract}

Keywords COVID-19 pandemic · Quality of life · Individual variables · Group variables

\section{Introduction}

Battling the novel coronavirus disease or COVID-19, many nations in the world have strained their human, health and economic resources. The speed in transmission of the virus has placed citizens and governments on tenterhooks, recognizing that this disease impacts not only the physical health of individuals, resulting in many fatalities the world over, but also their quality of life. Research on the viral outbreak has largely indicated negative outcomes such as depression and anxiety (Wang et al. 2020a), feelings of fear, stress and worry (Ahorsu et al. 2020; Bao et al. 2020), psychological distress (Rehman et al. 2020) and even stigma and xenophobia towards people suspected of being infected with the disease (Mamun and Griffiths 2020). Reportedly, fear of the disease has in many cases even led to suicides (Suicide leading cause for over 300 lockdown deaths in India, says The

Korsi Dorene Kharshiing

korsidk@gmail.com

1 Department of Psychology, Jamia Millia Islamia, New Delhi 110025, India

2 Department of Psychology, Aligarh Muslim University, Aligarh 120022, India
Economic Times (2020). Essentially, much of the evidence focus on adverse outcomes of the disease, necessitating an empirical shift towards COVID-19 outcomes that are preventive as well as positive, such as quality of life. There are some researches on preventive health behavior (Yıldirım et al. 2020; blinded for review, 2020) as well. It is a given, that the world has to live with the novel coronavirus, and hence, an understanding of QoL and the psychological and demographic factors affecting it, would indeed, facilitate in the rehabilitation of people. Therefore, it is imperative to examine a construct such as quality of life (henceforth QoL) in the ongoing COVID-19 pandemic, as it pertains to not only overall satisfaction in certain life areas, but also their importance (Lindner et al. 2016), that is at odds with living in times of the virus. These scholars also elucidate that quality of life is subjective and entails perceived satisfaction and importance of areas such as work, self-regard, recreation, opportunities to engage productively and creatively, possibilities of learning new things and friends and friendship in one's life. Clearly, this attainment of QoL is affected and disrupted in the present world today, that is riddled with the infectious disease.

Empirical evidence indicates that people show high levels of anxiety, perceived susceptibility and perceived severity 
(e.g., Kwok et al. 2020) to COVID-19 during the pandemic leading to preventive health behaviors. These factors play out at an individual level. Moreover, an individual's personal identity that drives his or her direction, convictions, goals and future expectations (Baray et al. 2009) may play a role in the adoption of health-related behaviors (e.g., social distancing) to combat the outbreak. Ample research evidence demonstrates the operation of optimistic bias wherein people tend to report themselves as less likely to experience negative events than others and more likely to experience events that are positive (Helweg-Larsen and Sheppard 2001; McKenna 1993; Perloff and Fetzer 1986). The role of optimistic bias in the novel coronavirus crisis has not been discounted as it leads people to believe that they would not be infected by the disease, or that the risks are lesser for them individually as compared to others (Laumas and Singh 2020).

The constructs of perceived susceptibility and perceived severity in combination to the COVID-19 outbreak, make up the Health Belief Model (HBM) (Champion and Skinner 2008) that is instrumental in explicating beliefs about one's vulnerability to, and gravity of the viral disease that informs behavior change, and thereby influences QoL. Lee (2020) argued that individuals may manifest symptoms of anxiety such as appetite loss, nausea, sleep disturbance, immobility and dizziness as manifestations of anxiety to COVID-19. Interestingly, a scrutiny of the relation between optimistic bias and perceived susceptibility and severity to the coronavirus diseases showed that individuals who are optimistically biased tend to underestimate their perceived susceptibility and severity to the virus (Park et al. 2020). Personal identification (Baray et al. 2009) in times of the outbreak may drive individuals to reassess their own functioning in terms of their perceived personal risks and vulnerability that then leads them to engage in preventive health behaviors (Oh et al. 2020). The operation of these individual-based constructs including QoL are complex warranting a need to perhaps go beyond what is prescribed in HBM and re-examine the role of group-related variables through the prism of social identity approach.

What emerged in the narrative surrounding the pandemic of the novel coronavirus is the emphasis not merely on role of the individual, but more so on the collective or "we". Measures of social/physical distancing and wearing of face masks during the pandemic outline the need for ensuring that "others" are also protected from the infection. It is in this light, that the role of the group emerges to counter the spread of COVID-19 and to manage it. For people, collective action that warrants solidarity may be evident in their identification with their families, religious community and also with their nation. Clearly, a theoretical framework such as that of the Social Identity Approach (SIA) facilitates an understanding of how group dynamics play out in the present health crisis. For Sani and Bennett (2009), the family molds an individual throughout his or her lifespan and thus, is essential for self- understanding and definition. Studies showed that a person's religious affiliation or group not only creates his or her social identity influencing religious and secular behavior (Baray et al. 2009), but also prods that individual into action in social contexts (e.g., Postmes et al. 2006). During a crisis such as the COVID-19 pandemic, identification with the nation as a citizen is crucial not only for self-identification, but also for social comparisons with "other" relevant countries (Tajfel and Turner 1979; Jetten et al. 2020) in terms of measures to manage and tackle the outbreak. Perhaps, the salience of group identification with one's family, religious brethren and one's country may have bearing not only on desirable health behaviors, but more importantly on the qualitative aspects of one's life.

It is pertinent to recognize that in the current COVID-19 pandemic, the role of individual 'me' factors, through the Health Belief Model has been crucial to encouraging people to engage in preventive health behaviors (e.g., Yıldırım et al. 2020). However, what also needs consideration is the social character of the pandemic, that argues for a 'we' or collective mindset, to limit and arrest the virus through a social identity perspective. Given the importance of both individual and group-related variables on a complex phenomenon such as QoL, the interplay of HBM and SIA as theoretical prisms to understand the role of the former on the latter is considered relevant in the present paper.

The present research thus, seeks to examine the influence of individual (anxiety, perceived susceptibility and severity to COVID-19, optimistic bias and personal identity) and group factors (identification with family, religious group and nation), but also certain socio-demographic variables such as age, gender, level of education, income level and containment zone on QoL of people living in times of the COVID-19 pandemic. In addition, the present study aims to ascertain the relations between demographic, individual and group level variables. To achieve these objectives, the present study proposed the following hypotheses:

$\mathrm{H}_{1}$ : Demographic variables such as age, gender, educational level, containment zone and income level (Model 1) would significantly predict QoL.

$\mathrm{H}_{2}$ : Individual variables of COVID-19 anxiety, perceived susceptibility, perceived severity, optimistic bias and personal identity (Model 2) would significantly influence QoL.

$\mathrm{H}_{3}$ : Social identity comprising identification with family, religious group and nation (Model 3) would significantly predict QoL.

$\mathrm{H}_{4}$ : Model 2 (individual variables) would significantly influence QoL over and above Model 1(demographic variables); and social identity (Model 3) would significantly impact QoL over and above individual variables (Model 2). 


\section{Method}

The present research utilized a quantitative research design to assess and examine the influence of individual (anxiety, perceived susceptibility and severity to COVID-19, optimistic bias and personal identity) and group factors (identification with family, religious group and nation) on QoL of people during the COVID-19 pandemic in India using standardized measures. The role of certain socio-demographic variables such as age, gender, level of education, income level and containment zone on QoL is also examined.

\section{Sample}

The data for the present study was collected from 305 Indian respondents using the convenience sampling method to contact or reach the participants. The inclusion criteria for the sample was: (i) participants were Indians residing in various regions of India such as Delhi and National Capital region (NCR), Mumbai, Shillong and Belgaum; (ii) aged 18 years and above; (iii) literate and (iv) had access to a smartphone or computer/laptop and internet for completion of the survey. Characteristics of this sample are depicted in Table 1.

\section{Procedure}

The data was collected electronically or 'online' through a Google form from 8th May 2020 to 31st May 2020 from Indians residing in various regions in India. E-mail and online platforms such as Whatsapp and Linkedin were used to circulate the Google form and collect the data. Respondents were informed about the purpose of the study, the voluntary nature of their participation and the option to also discontinue at any point of time. Participants' informed consent in the study was also taken and they were assured that their responses would be kept anonymous and confidential.

\section{Measures}

\section{Measures of Individual Variables}

COVID-19 Anxiety COVID-19 anxiety was measured using six items with high factor loadings, derived from a 12-item scale (Blinded for review, 2020). All items are measured on a 5-point scale, ranging from never (0) to always (4). The sample items include, 'I am unable to relax due to the constant threat that COVID-19 poses to our health" and 'Thinking/hearing/watching people who were infected and died make me frightened and distressed'. Scoring on this measure entailed summing up of the scores on all items with a higher score indicating more anxiety and a lower score indicative of less anxiety. Cronbach's alpha computed was 0.870 .

Perceived Susceptibility and Perceived Severity Assessment of perceived susceptibility and perceived severity has been derived from items developed by Champion and Skinner (2008). Perceived susceptibility is measured by four items with sample items being, "My chances of getting COVID-19 are great" and "My physical health makes it more likely that I will get COVID-19". Perceived severity is measured through six items in terms of physical symptoms of fear, financial problems and long term effects of the disease. Sample items include, "When I think about COVID-19 my heart beats faster", and "My financial security would be endangered if I got COVID-19". The items of both the constructs are measured on a 5-point scale ranging from strongly disagree (1) to strongly agree (5). On both these measures, scoring involves summation of scores on
Table 1 Sample characteristics $(\mathrm{N}=305)$

\begin{tabular}{llll}
\hline Variable & Level & Frequency & Percent \\
\hline Age & 18-78 years & - & - \\
Gender & (Mean=31.81; SD=11.31) & & \\
& Male & 112 & 36.7 \\
Educational level & Female & 193 & 63.3 \\
& Senior secondary (10+2) & 16 & 5.2 \\
& Graduate degree & 84 & 27.5 \\
& Post-graduate degree & 192 & 63 \\
Containment zone & Ph.D. degree & 13 & 4.3 \\
& Living in containment zone & 96 & 13.15 \\
Income level (per month) & Not living in containment zone & 209 & 68.5 \\
& Below 25,000 Rupees & 32 & 10.5 \\
& 25,000-50,000 Rupees & 52 & 17 \\
& 50,000-75,000 Rupees & 66 & 21.6 \\
& Above 75,000 Rupees & 155 & 50.8 \\
\hline
\end{tabular}


all items. A higher score on each measure is indicative of perceived severity of the disease and susceptibility to it, and a lower score is indicative otherwise. Cronbach's alpha coefficient for perceived susceptibility is 0.823 and for perceived severity is 0.786 .

Optimistic Bias Optimistic bias was assessed through two items that were written using Helweg-Larsen and Sheppard's (2001) direct method. Item 1 was stated as, 'Compared to other people of your age and sex, how likely are you to get COVID-19 during the current time?' and Item 2 was stated as, 'Compared to other people of your socioeconomic class, how likely are you to get COVID-19 during the current time?'. The scale was marked by using two anchoring points i.e., $(-3)$ indicative of 'much less likely than most people', and $(+3)$ indicative of 'much more likely than most people'. The procedure for scoring entailed the summing of scores on the two items, with a higher score indicating higher optimistic bias and vice-versa. Cronbach's alpha coefficient was found to be 0.646 on the current sample.

Personal Identity Baray et al. (2009) scale of 'Personal identity strength' comprising five items is utilised to measure personal identity. The measure has a five-response mode ranging from (1) 'do not agree at all' to (5) 'agree completely'. Sample items include, "I know what I like and what I don't like" and "I know what my morals are". Scoring involves the addition of scores on all the items, with a higher score indicating higher personal identity strength and vice-versa. Cronbach's alpha for this measure is 0.828 .

\section{Measures of Group Variables}

Identification with Family The measure for identification with family has been adapted from the 'Group identification' scale by Jetten et al. (2005) that comprise five items with a seven-response mode ranging from (1) 'not at all' to (7) 'very much'. Sample items include, "I identify with my family members" and "I feel a strong sense of solidarity with my family members. On this measure, scoring entails a summation of item scores, with a higher score denoting greater family identification and a lower score indicating otherwise. Cronbach's alpha coefficient was 0.889 on the current sample.

Identification with Religious Group This measure of five items has also been adapted from the 'Group identification' scale by Jetten et al. (2005) with a seven-response mode ranging from (1) 'not at all' to (7) 'very much'. Some of the items of the measure are, "I identify with the members of my religious group, and "I value being a part of my religious group". Scoring for this measure involves the addition of scores on the items. A higher score is indicative of greater identification with one's religious group and vice-versa. Cronbach's alpha was 0.952 .

Identification with Nation The five items of identification with nation has been adapted from the 'Group Identification' scale (Jetten et al. 2005), with a seven-response mode indicating (1) 'not at all' to (7) 'very much'. Sample items include, "I identify as an Indian", "I feel strong ties with other Indians" and "I value being an Indian". On this scale, scoring requires the summation of scores on all five items, with a higher score indicating more national identification. A lesser score would indicate otherwise. The Cronbach's alpha for this measure was 0.936 .

\section{Quality of Life}

The Brunnsviken brief quality of life scale (BBQ) by Lindner et al. (2016) is a 12-item measure used to assess QoL. The factors assessed are leisure time, view on life, creativity, learning, friends and friendships, and view of self. The measure has a four-response mode ranging from (1) 'do not agree at all' to (4) 'agree completely'. Some of the sample items include, "Over the course of last month, I have been satisfied with my leisure time: I have had the opportunity to do what I want in order to relax and enjoy myself" and "Over the course of last month, how I view my life has been important for my quality of life". Scoring on this measure entails the summing up of scores on all items with a higher score indicating greater $\mathrm{QoL}$ and a lower score, otherwise. Cronbach's alpha for quality of life was found to be 0.935 .

\section{Analysis of Results and Interpretation}

Data was analyzed using SPSS 22 and hierarchical regression analysis was utilized to test the models. Table 1 above reveal the sample characteristics on certain demographic variables, wherein mean age of the sample is 31.81 . Female participation (63.3 percent) was higher as compared to that of males (36.7 percent). Most of the respondents are graduates ( 27.5 percent) and postgraduates (63 percent), with reported incomes per month largely above 50,000 rupees. Many respondents (13.15 percent) also report living in containment zones during the pandemic.

Respondents reported higher QoL and lower optimistic bias (see Table 2). Social identification with one's family and with one's nation for people is higher as evident from the mean values in Table 2, however, it was just average with the religious group. People's perceived susceptibility, severity as well as anxiety to COVID-19 is on the lower side.

Correlation coefficients in Table 3 above show positive significant relations between COVID-19 anxiety, and perceived susceptibility and severity $(0.302$ and 0.557 at 
Table 2 Descriptive statistics of variables

\begin{tabular}{llllc}
\hline Variables & $\mathrm{N}$ & Mean & Standard deviation & $\begin{array}{l}\text { Cronbach's } \\
\text { alpha }\end{array}$ \\
\hline COVID-19 anxiety & 305 & 12.04 & 4.889 & .870 \\
Perceived susceptibility & 305 & 10.41 & 3.037 & .823 \\
Perceived severity & 305 & 16.63 & 4.719 & .786 \\
Optimistic bias & 305 & 2.52 & .881 & .646 \\
Personal identity & 305 & 21.75 & 3.057 & .828 \\
Identification with family & 305 & 30.26 & 5.712 & .889 \\
Identification with religious group & 305 & 22.14 & 9.124 & .952 \\
Identification with nation & 305 & 30.53 & 6.181 & .935 \\
Quality of life (QoL) & 305 & 33.91 & 10.158 & .935 \\
\hline
\end{tabular}

Table 3 Correlation coefficients of variables

\begin{tabular}{|c|c|c|c|c|c|c|c|c|c|}
\hline Variable & 1 & 2 & 3 & 4 & 5 & 6 & 7 & 8 & 9 \\
\hline Covid-19 anxiety & 1 & & & & & & & & \\
\hline Perceived susceptibility & $.302 * *$ & 1 & & & & & & & \\
\hline Perceived severity & $.557 * *$ & $.152 * *$ & 1 & & & & & & \\
\hline Optimistic bias & .045 & $.253 * *$ & .082 & 1 & & & & & \\
\hline Personal identity & -.053 & -.069 & -.003 & -.018 & 1 & & & & \\
\hline Identification with family & -.050 & -.035 & -.089 & -.091 & $.361 * *$ & 1 & & & \\
\hline Identification with religious group & -.007 & $-.146^{*}$ & .098 & -.050 & $.282 * *$ & $.291 * *$ & 1 & & \\
\hline Identification with nation & -.067 & -.073 & -.004 & -.021 & $.288 * *$ & $.335^{* *}$ & $.239 * *$ & 1 & \\
\hline Quality of life & $-.125 *$ & -.101 & .014 & .007 & $.384 * *$ & $.281 * *$ & $.266^{* *}$ & $.299^{* *}$ & 1 \\
\hline
\end{tabular}

${ }^{*} p<0.05, * * p<0.01$

$p<0.01)$. Individuals' perceived susceptibility is also positively related to the severity of the disease $(0.152$ at $p<0.01)$ and their optimistic bias $(0.253$ at $p<0.01)$. QoL is significantly related to personal identity and social identification of family, religious group and nation (see Table 3). Moreover, a low yet significant negative relationship exists between anxiety over COVID-19 and QoL $(-0.125$ at $p<0.05)$.

Table 4 showed that demographic variables (Model 1) did not influence QoL $(\mathrm{F}=1.254, p=0.264)$. From the individual level variables (Model 2), COVID-19 anxiety $(\beta=-0.135, p=0.051)$ and personal identity $(\beta=0.376$, $p<0.001)$ emerged as significant predictors of QoL. COVID-19 anxiety predicted QoL negatively, while personal identity predicted QoL significantly in a positive direction. In terms of social identity (Model 3), identification with family $(\beta=0.123, p=0.039)$ and identification with the nation $(\beta=0.156 . p=0.006)$ were significant predictors of QoL. Effect size of Model 2 over Model 1 was found to be 0.185 and from Model 3 over Model 2 was found to be 0.176 . Both these effect sizes indicated their medium effect as per Cohen (1988). It implies that individual level factors (notably personal identity and COVID-19 anxiety) significantly impacted QoL over and above demographics. In a similar vein, it can also be concluded that group based identities (notably identification with nation as well as with one's families) impacted QoL over and above individual level predictors.

\section{Discussion}

Given that COVID-19 is significantly altering the way human beings are living their lives, it is pertinent to examine influences on quality of life such as demographic factors, individual and group variables, which is what the present study attempts to do. Perhaps, since most of the study participants were younger, more literate, qualified with higher degrees, better income earnings and living predominantly in non-containment zones, their QoL was not significantly impacted as shown by the mean value. On the contrary, Nguyen et al. (2020) reported that people with higher levels of educational attainment and incomes were associated with higher QoL particularly related to health concerns. Thus, findings in this study invalidate Hypothesis 1.

Evidence from the present study indicate that individual level variables of COVID-19 anxiety and personal identity significantly predicted QoL. The former influenced QoL negatively and the latter, positively. Essentially, this would 


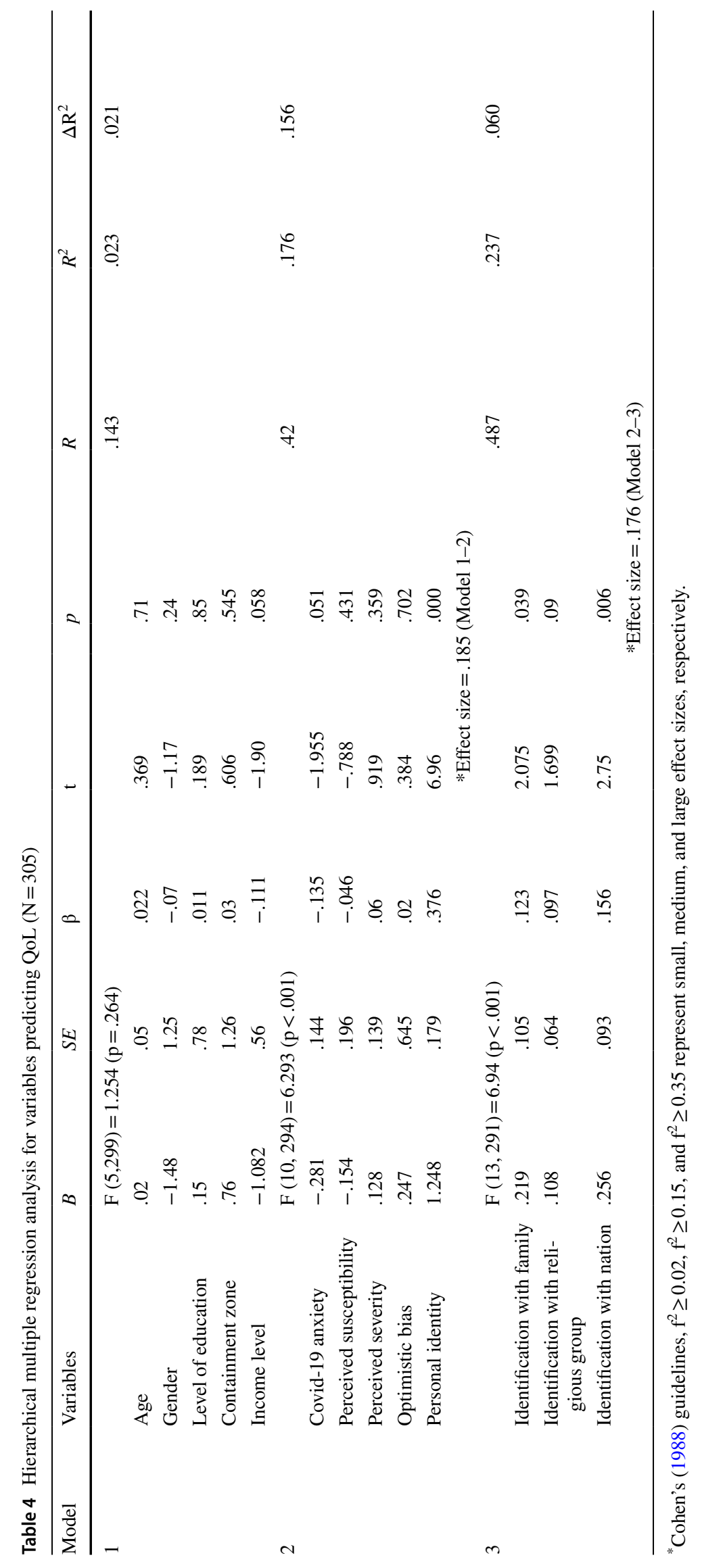


mean that for the sample respondents, heightened anxiety over the viral disease would also lower QoL. Perhaps, the view that the virus heralds 'the end of the world experience', thereby leading to anxiety and distress (Fardin 2020), that may affect negatively one's relationships and creative and learning endeavors. Anxiety about the COVID-19 threat may give rise to uncertainty and confusion (Limcaoco et al. 2020; Wang et al. 2020a, b) hindering qualitative living. On the contrary, personal identity which provides a clear sense of life direction, certainty of their goals and future expectations (Baray et al. 2009) may prod individuals in the present study to also positively alter and change their life in areas of friends, learning and creative activities including their views of themselves and others. In fact, many Chinese had reportedly started paying more attention to their health, relaxing, exercising and resting after the onset of the COVID-19 pandemic (Zhang and Ma 2020). What is clear from the results of this research is that participants' optimistic bias, their perception of lack of susceptibility to the virus and of it not being severe have had no effect on their QoL. Research findings, therefore, partially confirm Hypothesis 2.

It is increasingly apparent that the nature of the coronavirus outbreak necessitated group work to contain its transmission and manage it. Empirical evidence from the present study show that social identification with family and nation significantly predicts QoL. Essentially, the pandemic is about group psychology that entails community participation and engagement (Jetten et al. 2020). Arguably, family identification and cohesion promote wellbeing and resilience (Stevenson et al. 2020), which may have also positively impacted QoL. In large scale disasters, people are likely to define themselves in terms of their shared identity (Drury 2012). In this pandemic too, such group memberships (e.g., based on family and nationality) are valued as a resource that bond and bind people together (Kwok et al. 2020) altering positively aspects of leisure, creative pursuits, friends and friendships, etc., in life. In addition, groups we identify with also serve as psychological resources (Haslam et al. 2018; Jetten et al. 2012) in giving our lives meaning, purpose and self-worth. In the context of national identification in COVID-19 times, selective intergroup comparisons are made (Tajfel and Turner 1979) about other nations' responses and management of the outbreak which puts the national ingroup in a positive light as evident in the case of the United States of America (Mackey 2020). Identification of Indians with the clarion call of banging utensils by the Prime Minister on 22 March 2020 to demonstrate support for frontline health workers battling the virus is obvious (Coronavirus: Indians bang pots and pans to support fight (2020) that may impact positively on their notions of themselves, creative pursuits, friendships and learning activities. Thus, results from this research partially confirm Hypothesis 3.
Findings from the present study reveal that QoL is significantly influenced by individual variables (notably, personal identity and COVID-19 anxiety) over and above demographics. Further, social or group-based identities (such as family and national identification) are seen to impact QoL significantly over and above individual variables. It can be said therefore, that Hypothesis 4 is validated. Clearly, the findings find support from Lau et al. (2003) who observed that residents in Hong Kong were largely unaffected by the SARS epidemic due to increased family and community support and care. Indeed, Jetten et al. (2020) opined that in times of stress throughout the COVID-19 crisis, in-groups serve as an important source of support.

\section{Conclusion}

The pandemic of COVID-19 has made apparent the nonsignificant influence of age, gender, education, income and containment zone on the qualitative aspects of people's lives. Individual factors, notably, anxiety over the disease and personal identity also impact QoL. In a similar vein, group-based or social identification of individuals, particularly that of their family and their nation have impacted their quality of life. Interestingly, anxiety, perceived susceptibility and severity of COVID-19, along with personal identity and optimistic bias predicted QoL over and above the effects of demographic variables. Finally, the effect of group identities (family, religious group and nation) is above that of personal or individual factors in predicting QoL. Given that the pandemic is ongoing, it is necessary for people, government agencies and health practitioners to recognize the necessity of leading and living qualitative lives.

\section{Limitations}

A shortcoming of this study is the electronic form of data generation through Google form, which limits accessibility to a larger population. Sample characteristics in the research demonstrate more female than male participants; most respondents were highly educated, more affluent and were largely living in non-containment areas, thus limiting the generalizability of the findings to the general population. Finally, given the evolving complex nature of the ongoing viral pandemic, the present research's one-time crosssectional data may not be adequate in explicating QoL of people. 


\section{Research Implications}

The absence of a vaccine or medicine to treat COVID-19 is indicative of the prolonged stay of the virus in the lives of people. As indicated by the present study, QoL is necessary especially in times of crisis, that mandates people to manage themselves, their activities and their relationships effectively. Given the role of group affiliations in promoting QoL, even more than individual factors, emphasis on empowering social units such as family and citizens to arrest the transmission and stigma of the disease should be focused by agencies in the community and government as part of policymaking. Perhaps, the need of the hour, is to rally citizens together as a unified entity under a superordinate national identity, that would be crucial in not only determining QoL, but also ridding away stigma, prejudice and even discrimination during the pandemic. Implementation and advisories of social or physical distancing affecting leisure and creative pursuits, work and relationships necessitates finding novel ways and means of maintaining that the same life activities and relations go unhindered for people of all age groups. Finally, this research alludes to the need to tailor intervention programs by mental health practitioners and other stakeholders, to aid people in living their lives productively, in spite of COVID-19.

Author Contributions All the authors equally contributed in the conceptualization, data collection, data analysis, initial paper writing and in giving the paper its final shape. Authorship as mentioned above is in an alphabetic order.

Funding No financial support was received for this study from any source.

\section{Compliance with Ethical Standards}

Conflict of interest All the authors declare that they have no conflict of interest.

Ethical Approval All procedures followed were in accordance with the ethical standards of the responsible committee on human experimentation (institutional and national) and with the Helsinki Declaration of 1975, as revised in 2000 (5). Informed consent was obtained from all participants for being included in the study.

Informed Consent Informed consent was sought from the participants before going ahead with data collection.

\section{References}

Ahorsu, D., Lin, C., Imani, V., Saffari, M., Griffiths, M., \& Pakpour, A. (2020). The fear of COVID-19 scale: Development and initial validation. International Journal of Mental Health and Addiction. https://doi.org/10.1007/s11469-020-00270-8.
Bao, Y., Sun, Y., Meng, S., Shi, J., \& Lu, L. (2020). 2019-nCoV epidemic: Address mental health care to empower society. The Lancet, 395(10224), e37-e38. https://doi.org/10.1016/s0140 -6736(20)30309-3.

Baray, G., Postmes, T., \& Jetten, J. (2009). When i equals we: Exploring the relation between social and personal identity of extreme right-wing political party members. British Journal of Social Psychology, 48(4), 625-647. https://doi.org/10.1348/014466608x 389582.

Champion, V. L., \& Skinner, C. S. (2008). The health belief model. In K. Glanz, B. Rimer, \& K. Vishwanath (Eds.), Health behavior and health education: Theory research and practice (pp. 45-65). San Francisco, CA: Jossey-Bass.

Cohen, J. E. (1988). Statistical power analysis for the behavioral sciences. Hillsdale, NJ: Lawrence Erlbaum Associates Inc.

Coronavirus: Indians bang pots and pans to support fight (2020). BBC News. Retrieved March 22, 2020 from https://www.bbc.com/news/ av/world-asia-india51997699/coronavirus-indians-bang-pots-andpans-to-support-fight.

Drury, J. (2012). Collective resilience in mass emergencies and disasters. In J. Jetten, C. Haslam, \& S. A. Haslam (Eds.), The social cure: Identity, health and well-being (pp. 195-215). New York: Psychology Press.

Fardin, M. A. (2020). COVID-19 and anxiety: A review of psychological impacts of infectious disease outbreaks. Archives of Clinical Infectious Diseases. https://doi.org/10.5812/archcid.102779.

Haslam, S. A., McMahon, C., Cruwys, T., Haslam, C., Greenaway, K. H., Jetten, J., et al. (2018). Social cure, what social cure? The propensity to underestimate the importance of social factors for health. Social Science and Medicine, 198, 14-21.

Helweg-Larsen, M., \& Sheppard, J. A. (2001). Do moderators of the optimistic bias affect personal or target risk estimates? A review of the literature. Personality and Social Psychology Review, 5(1), 74-95.

Jetten, J., Haslam, C., \& Haslam, S. A. (Eds.). (2012). The social cure: Identity, health and well-being. New York: Psychology Press.

Jetten, J., Reicher, S., Haslam, A., \& Cruwys, T. (2020). A social identity analysis of COVID-19. In J. Jetten, S. Reicher, A. Haslam, \& T. Cruwys (Eds.), Together apart. The psychology of COVID-19 (pp. 20-31). London: Sage Publications.

Jetten, J., Schmitt, M., Branscombe, N., \& McKimmie, B. (2005). Suppressing the negative effect of devaluation on group identification: The role of intergroup differentiation and intragroup respect. Journal of Experimental Social Psychology, 41(2), 208-215. https:// doi.org/10.1016/j.jesp.2004.07.008.

Kwok, K. O., Li, K. K., Chan, H. H., Yi, Y. Y., Tang, A., Wei, W. I., et al. (2020). Community responses during the early phase of the COVID-19 epidemic in HongKong: Risk perception, information exposure and preventive measures. Cold Spring Harbor: Cold Spring Harbor Laboratory.

Lau, J. T., Yang, X., Tsui, H., \& Kim, J. H. (2003). Monitoring community responses to the SARS epidemic in Hong Kong: From day 10 to day 62. Journal of Epidemiology and Community Health, $57,864-870$.

Laumas, A., Singh, S. (2020). A behavioral cheatsheet to India's COVID-19 response. Retrieved May 2, 2020 from https://www. cnbctv18.com/views/a-behavioral-cheatsheet-to-indias-covid-19response-5895041.htm.

Lee, S. A. (2020). Coronavirus anxiety scale: A brief mental health screener for COVID-10 related anxiety. Death Studies, 44(7), 393-401. https://doi.org/10.1080/07481187.2020.1748481.

Limcaoco, R. S. G., Mateos, E. M., Fernandez, J. M., \& Roncero, C. (2020). Anxiety, worry and perceived stress in the world due to the COVID-19 pandemic (unpublished) Preliminary results. MedRxiv. https://doi.org/10.1101/2020.04.03.20043992. 
Lindner, P., Frykheden, O., Forsstrom, D., Andersson, E., Ljotsson, B., Hedman, E., et al. (2016). The Brunnsviken brief quality of life scale(BBQ): Development and psychometric evaluation. Cognitive Behaviour Therapy, 45(3), 182-195. https://doi. org/10.1080/16506073.2016.1143526.

Mackey, R. (2020). Through creative accounting, Trump tries to cast America's death toll as an achievement. The Intercept. Retrieved May 3, 2020 from https://theintercept.com/2020/05/02/creativeaccounting-trump-tries-cast-americas-death-toll-achievement/.

Mamun, M., \& Griffiths, M. (2020). First COVID-19 suicide case in Bangladesh due to fear of COVID- 19 and xenophobia: Possible suicide prevention strategies. Asian Journal of Psychiatry, 51, 102073. https://doi.org/10.1016/j.ajp.2020.102073.

McKenna, F. P. (1993). It won't happen to me: Unrealistic optimism or illusion of control? British Journal of Psychology, 84, 39-50.

Nguyen, H. C., Nguyen, M. H., \& Do., B.N... \& Duong, T.V., (2020). People with suspected COVID-19 systems were more likely depressed and had lower health-related quality of life: The potential benefit of health literacy. Journal of Clinical Medicine, 9, 965. https://doi.org/10.3390/jcm9040965.

Oh, S. H., Lee, S. Y., \& Han, C. (2020). The effects of social media on preventive behaviors during infectious disease outbreaks: The mediating role of self-reliant emotions and public risk perception. Health Communication. https://doi.org/10.1080/10410 236.2020.1724639.

Park, T., Ju, I., Ohs, J. E., \& Hinsley, A. (2020). Optimistic bias and preventive behavioral engagement in the context of COVID-19. Research in Social and Administrative Pharmacy. https://doi. org/10.1016/j.sapharm.2020.06.004.

Perloff, L. S., \& Fetzer, B. K. (1986). Self-other judgements and perceived vulnerability to victimization. Journal of Personality and Social Psychology, 50, 502-510.

Postmes, T., Baray, G., Haslam, S. A., Morton, T., \& Swaab, R. I. (2006). The dynamics of personal and social identity formation. In T. Postmes \& J. Jetten (Eds.), Individuality and the group: Advances in social identity (pp. 215-236). London: Sage.

Rehman, U., Shahnawaz, M. G., Khan, N. H., Kharshiing, K. D., Khursheed, M., Gupta, K., et al. (2020). Depression, anxiety, stress among Indians in times of COVID-19 Lockdown. Community Mental Health Journal. https://doi.org/10.1007/s10597-02000664-x.

Sani, F., \& Bennett, M. (2009). Children's inclusion of the group in the self: Evidence from a self-ingroup confusion paradigm. Developmental Psychology, 45, 503-510.
Stevenson, C., Costa, S., Wakefield, J. R. H., Kellezi, B., \& Stack, R. J. (2020). Family identification facilitates coping with financial distress: A social identity approach to family financial resilience. Journal of Economic Psychology, 78, 102271. https://doi. org/10.1016/j.joep.2020.102271.

Suicide leading cause for over 300 lockdown deaths in India, says study. (2020). The Economic Times. Retrieved May 5, 2020 from https://economictimes.indiatimes.com/news/politics-and-natio n/suicide-leading-cause-for-over-300-lockdown-deaths-in-india -saysstudy/articleshow/75519279.cms.

Tajfel, H., \& Turner, J. C. (1979). An integrative theory of intergroup conflict. In W. G. Austin \& S. Worchel (Eds.), The social psychology of intergroup relations (pp. 33-48). Belmont, California: Brooks/Cole.

Wang, Y., Di, Y., Ye, J., \& Wei, W. (2020a). Study on the public psychological states and its factors during the outbreak of coronavirus disease 2019 (COVID-19 in some regions of China. Psychology, Health and Medicine. https://doi.org/10.1080/13548 506.2020.1746817.

Wang, C., Pan, R., Wan, X., Tan, Y., Xu, L., Ho, C. S., et al. (2020b). Immediate psychological responses and associated factors during the initial stage of the 2019 coronavirus disease (COVID-19) epidemic among the general population in China. International Journal of Environmental Research and Public Health, 17, 1729.

Yıldırım, M., Geycer, E., \& Akgul, O. (2020). The impacts of vulnerability, perceived risk, and fear on preventive behaviors against COVID-19. Psychology, Health and Medicine. https://doi. org/10.1080/13548506.2020.1776891.

Zhang, Y., \& Ma, Z. F. (2020). Impact of the COVID-19 pandemic on mental health and quality of life among local residents in Liaoning province, China: A cross-sectional study. International Journal of Environmental Research and Public Health, 17, 2381. https:// doi.org/10.3390/ijerph17072381.

Publisher's Note Springer Nature remains neutral with regard to jurisdictional claims in published maps and institutional affiliations. 